\title{
Tracheal instillation of urban $\mathrm{PM}_{2.5}$ suspension promotes acute cardiac polarization changes in rats
}

\author{
L.F. Maatz, G.J.A. Wood, D.H.R.F. Rivero and P.H.N. Saldiva \\ Laboratório de Poluição Atmosférica Experimental, Departamento de Patologia, Faculdade de \\ Medicina, Universidade de São Paulo, São Paulo, SP, Brasil
}

Correspondence to: P.H.N. Saldiva, Departamento de Patologia, Faculdade de Medicina, USP, Av. Dr. Arnaldo, 455, 1ㅇandar, sala 1226, 01246-903 São Paulo, SP, Brasil

Fax: +55-11-3068-0072. E-mail: pepino@usp.br

\begin{abstract}
The mechanisms by which $\mathrm{PM}_{2.5}$ increases cardiovascular mortality are not fully identified. Autonomic alterations are the current main hypotheses. Our objective was to determine if $\mathrm{PM}_{2.5}$ induces acute cardiac polarization alterations in healthy Wistar rats. $\mathrm{PM}_{2.5}$ samples were collected on polycarbonate filters. Solutions containing 10,20 , and $50 \mu \mathrm{gPM}_{2.5}$ were administered by tracheal instillation. $\mathrm{P}$ wave duration decreased significantly at $20 \mu \mathrm{g}(0.99 \pm 0.06,0.95 \pm 0.06$, and $0.96 \pm 0.07 ; \mathrm{P}<0.001)$, and $50 \mu \mathrm{g}(0.98 \pm 0.06,0.98 \pm 0.07$, and $0.96 \pm 0.08 ; 60,90$ and $120 \mathrm{~min}$, respectively) compared to blank filter solution $(P<0.001)$. $P R$ interval duration decreased significantly at $20 \mu \mathrm{g}(0.99 \pm 0.06,0.98 \pm 0.07$, and $0.97 \pm 0.08)$ and $50 \mu \mathrm{g}(0.99 \pm 0.05,0.97 \pm 0.0$, and $0.95 \pm 0.05 ; 60,90$, and 120 min, respectively) compared to blank filter and $10 \mu \mathrm{g}(\mathrm{P}<0.001)$. QRS interval duration decreased at 20 and $50 \mu \mathrm{g}$ in relation to blank filter solution and 10 $\mu \mathrm{g}(\mathrm{P}<0.001)$. QT interval duration decreased significantly $(\mathrm{P}<0.001)$ with time in animals receiving $20 \mu \mathrm{g}(0.94 \pm 0.12,0.88 \pm 0.14$, and $0.88 \pm 0.11)$ and $50 \mu \mathrm{g}(1.00 \pm 0.13 ; 0.97 \pm 0.11$ and $0.98 \pm 0.16 ; 60,90$ and $120 \mathrm{~min}$, respectively) compared to blank filter solution and $10 \mu \mathrm{g}(\mathrm{P}<0.001) . \mathrm{PM}_{2.5}$ induced reduced cardiac conduction time, within a short period, indicating that depolarization occurs more rapidly across ventricular tissue.
\end{abstract}

Key words: ECG alterations; Particulate matter; $\mathrm{PM}_{2.5} ;$ Wave segments; Tracheal instillation; Cardiovascular disease

Research supported by CNPq (\#803070/87-0) and LIM-HCFMUSP (Institute of the Laboratories of Medical Investigation, Clinical Hospital, School of Medicine, University of São Paulo). Publication supported by FAPESP.

Received April 6, 2008. Accepted January 12, 2009

\section{Introduction}

Numerous studies have associated air pollution, especially its particulate component, with hospital admissions and mortality due to cardiovascular diseases $(1,2)$. When exposed to particulate matter (PM), individuals with cardiac disorders experience acute cardiovascular events such as myocardial infarction (3-7), as well as release of inflammatory mediators (8-11). Additionally, increased plasma viscosity and other changes in bloodrelated parameters such as fibrinogen levels or red blood cell counts have been demonstrated after particle inhalation $(12,13)$.

The mechanisms by which PM increases mortality through cardiovascular disease are not completely clear, but probably include autonomic effects or direct myocardial toxicity of PM components. It is plausible that PM evokes the beginning of pulmonary inflammation triggered by reflexes that may affect cardiovascular function (14). Changes in autonomic control may induce alterations in vascular permeability, edema and systemic inflammation, causing heart failure and sudden cardiac death (15). Epidemiologic studies have also demonstrated a consistent link between sudden cardiac death and particulate air pollution (16), with changes such as increased QRS duration and arrhythmias (17), alteration of heart rate variability $(\mathrm{HRV})(18,19)$ and repolarization abnormalities (20-23) increasing morbidity and mortality. 
Previous epidemiological studies have shown that daily variations in particulate air pollution induced a decrease of HRV $(24,25)$ and an increase of arrhythmias (26). Studies focusing on the onset of myocardial infarction in patients exposed to traffic in their routine activities indicated that the most critical time window is within one hour of the onset of clinical manifestations (27). Controlled exposure of patients with coronary insufficiency during moderate exercise indicates that PM acutely increases the magnitude of ischemic burden to myocardial tissue (28). In addition, an acute increase in the risk of cardiac tachyarrhythmias was observed in patients with implanted cardioverter defibrillators exposed to air pollution during routine activities (29). Previous studies from our group have demonstrated that PM instillation in rats promotes an acute decrease in HRV after $1 \mathrm{~h}(30)$, as well as pulmonary arteriole vasoconstriction, hematological changes and pulmonary inflammation after $24 \mathrm{~h}$ (31).

Recent publications have reported that repolarization abnormalities play a role in arrhythmogenesis $(32,33)$. In this context, analysis of the duration of wave intervals in electrocardiograms (ECG) could potentially identify patients at risk for cardiac death and sudden cardiac death. The objective of the present study was to determine if fine particulate matter is able to induce acute cardiac polarization alterations during the first $2 \mathrm{~h}$ of ECG recording in healthy Wistar rats. To assess the effects of environmental PM concentration we used solutions containing 10, 20 , and $50 \mu \mathrm{g} \mathrm{PM}_{2.5}$ administered by tracheal instillation.

\section{Material and Methods}

\section{Animals}

Adult male Wistar rats (3 months of age) weighing $\sim 250 \mathrm{~g}$ were obtained from the animal house of the School of Medicine of the University of São Paulo. The animals were maintained at 22 to $23^{\circ} \mathrm{C}$ with controlled humidity and a 12- to 12-h light cycle. Food and water were available ad libitum. All animals received humane care in compliance with the Principles of Laboratory Animal Care published by the National Institutes of Health (NIH publication 86-23, revised 1985; http://oacu.od.nih. gov/regs/index.htm).

\section{Particle sampling and analysis}

$\mathrm{PM}_{2.5}$ (fine mode particles) samples were collected on 10 polycarbonate filters throughout the study using Harvard impactors (Air Diagnostics, USA) operating at 10 $\mathrm{L} / \mathrm{min}$ for $24 \mathrm{~h}$ and $\mathrm{PM}_{2.5}$ concentration was determined gravimetrically (34). The exposure site was located $<100$ $\mathrm{m}$ from a busy traffic corner in downtown São Paulo and in close proximity to a monitoring station of the State of São Paulo Sanitation Agency. At this intersection, it is estimated that approximately 83,941 cars, 9936 diesel vehicles and 6321 motorcycles circulate daily on the main street and 25,590 cars, 5299 diesel vehicles and 808 motorcycles circulate on the lateral street of the crossing. There are no industries or significant biomass sources in the surrounding area. Filters were weighed before and after collection to determine particle mass. After $\mathrm{PM}_{2.5}$ collection, the filters were maintained in an acclimatized environment and re-weighed. Particles were sampled in September 2006.

\section{Trace elements determination}

The comparative determination of trace elements present in $\mathrm{PM}_{2.5}$ was made on 10 filters using Energy Dispersive X-ray Fluorescence Spectrometer analysis (ED-XRF; EDX 700, Shimadzu Corporation Analytical Instruments Division, Japan). The spectrometer used a low power Rhtarget tube, voltage of 5 to $50 \mathrm{kV}$, and a current of 1 to 1000 $\mu \mathrm{A}$. The characteristic $\mathrm{X}$-ray radiation was detected by a Si (Li) detector. The analysis was made in a vacuum for the element range $\mathrm{Na}$ to $U$ on the $10-\mathrm{mm}$ filter surface. The non-exposed filters were used as blanks and their contribution was discounted from the results $(30,31)$.

\section{Filter extracts}

After ED-XRF analysis, aqueous suspensions of filters were prepared. The filters were submerged in distilled water and the filtrate was removed via agitation in an ultrasound water bath for $2 \mathrm{~h}$.

\section{Particulate matter instillation}

Forty rats were submitted to tracheal instillation of 0.5 $\mathrm{mL}$ of the following solutions: blank filter $(\mathrm{N}=10)$, a solution obtained by ultrasonication of a blank filter in distilled water; P 10 ( $N=10)$, a solution obtained by ultrasonication of a filter containing $\mathrm{PM}$ submerged in distilled water, containing $10 \mu \mathrm{PM}_{2.5}$; P 20 ( $\left.\mathrm{N}=10\right)$, a solution obtained by ultrasonication of a filter containing $\mathrm{PM}$ submerged in distilled water containing $20 \mu \mathrm{PM}_{2.5}$; P $50(N=10)$, a solution obtained by ultrasonication of a filter containing PM submerged in distilled water containing $50 \mu \mathrm{g} \mathrm{PM}_{2.5}$.

The $\mathrm{PM}_{2.5}$ amount instilled into each rat corresponded to the dose that would deposit in their lungs during $24 \mathrm{~h}$ of ambient exposure at concentrations similar to those of the study site, which had an annual average of $\mathrm{PM}_{2.5}$ of approximately $30 \mu \mathrm{g} / \mathrm{m}^{3}$ (35). Assuming that the ventilation of a resting adult rat is about $200 \mathrm{~mL} / \mathrm{min}$, the amount of $\mathrm{PM}_{2.5}$ inhaled would be about $9 \mu \mathrm{g} / \mathrm{m}^{3}$. Thus, our lowest 
dose represents a typical day in downtown São Paulo, while the higher doses are representative of particularly bad pollution days.

The instillation procedure was performed under anesthesia with $3 \%$ sodium pentobarbital $(30 \mathrm{mg} / \mathrm{kg}$ body weight, ip). The rats were submitted to tracheal intubation using an adapted pediatric laryngoscope and a 16-gauge polyethylene tube was inserted serving as an endotracheal tube. The solution $(0.5 \mathrm{~mL}$ of blank or extract suspensions) was instilled during three separate inspirations through the endotracheal tube coupled to a syringe.

\section{Electrocardiographic data acquisition and analysis}

An ECG was recorded through stainless steel needles implanted under the skin during anesthesia after tracheal intubation. Electrocardiogram electrodes were implanted subcutaneously in a Lead II configuration (right arm, left leg, and right leg) with one retrocordial derivation. We employed a device primarily developed for use in human ECGs (TEB - Tecnologia de Engenharia Brasileira ${ }^{\circledR}$ ), which was adapted for use in rodents. ECG signals were band-pass filtered, amplified, digitized $(500 \mathrm{~Hz})$ and stored in a microcomputer (30).

ECGs were recorded during five consecutive minutes for each period of analysis (pre-instillation, 30, 60, 90, and 120 min after instillation) and were analyzed manually by two observers for $P$ wave (which represents the wave of depolarization that spreads from the sinoatrial node throughout the atria), PR interval (period of time from the onset of the $P$ wave to the beginning of the QRS complex), QRS complex (which represents ventricular depolarization), and QT interval (which represents the time for both ventricular depolarization and repolarization). The program automatically counts each wave segment selected by the researcher with the mouse cursor on a computer screen. Wave segments were coded for blind analysis and the code was only revealed when the studies were completed. We analyzed 40 cardiac cycles for each period of analysis.

Additionaly, we assessed heart rate (HR) and HRV through the standard deviation of beat-to-beat intervals (SDNN). Changes were computed by inspecting ECGs recorded during five consecutive minutes for each period of analysis. Considering that the HR in our animals was consistently over 200 beats per minute, we analyzed at least 1000 beats. HR, calculated as the reciprocal of mean beat-to-beat interval, and the SDNN were calculated immediately before (Pre) and 30, 60, 90, and 120 min after instillation. After regaining consciousness, the animals were returned to their cages and taken to the vivarium.

\section{Statistical analysis}

The significance of wave segment duration and of HR and HRV results was determined by employing general linear models using dependent variables for the difference between the various times of measurements after instillation and the values measured before instillation. The Bonferroni test was employed for post hoc analysis. The level of significance was set at $5 \%$. All statistical calculations were performed with the aid of the SPSS v 10.0 package.

\section{Results}

None of the animals under study died during the course of the experiment. One animal died during the night after instillation of $10 \mu \mathrm{g} \mathrm{PM}_{2.5}$. Autopsy revealed pulmonary congestion and neutrophilic alveolar infiltrate.

Table 1 reports the percentage of each element collected on 10 filters measured by ED-XRF. Initially, a qualitative and semi-quantitative analysis of elements from $\mathrm{Na}$ to $U$ was performed. After semi-quantitative analysis, the resultant spectrum was generated according to the detectable elements of interest. In general, the concentrations of sodium, silicon, calcium, and iron are representative of crustal and soil resuspension. Sulfur, which is characteristic of vehicle emissions, was the most representative element (37.59\%).

Table 2 provides the HRV results assessed by SDNN values. While there was no significant difference in SDNN among groups, we did observe a trend of reduction of

Table 1. Elemental composition and concentration of $\mathrm{PM}_{2.5}$ particles.

\begin{tabular}{lc}
\hline Element & Values \\
\hline Sodium & $12.1 \%$ \\
Aluminum & $0.83 \%$ \\
Silicon & $13.1 \%$ \\
Phosphorus & $0.005 \%$ \\
Sulfur & $37.6 \%$ \\
Potassium & $4.21 \%$ \\
Calcium & $12.1 \%$ \\
Titanium & $1.32 \%$ \\
Iron & $14.5 \%$ \\
Copper & $0.74 \%$ \\
Zinc & $2.42 \%$ \\
Lead & $0.49 \%$ \\
Vanadium & $0.26 \%$ \\
Nickel & $0.34 \%$ \\
\hline
\end{tabular}

Data are reported as mean percent of each element collected on 10 filters measured by energy dispersive $X$-ray fluorescence spectrometer analysis. 
SDNN values with the large dose $(50 \mu \mathrm{g})$, the same dose that provoked a significant SDNN decrease in our previous study (30). Tables 3 and 4 present HR and absolute measures of $\mathrm{P}, \mathrm{PR}, \mathrm{QRS}$, and QT wave segment duration for the various groups, respectively. There were no significant differences in these parameters.

Table 5 lists the descriptive statistics of variations in relation to the pre-instillation time of each of the ECG

Table 2. Heart rate variability assessed by the standard deviation of beat-to-beat intervals (SDNN) for all experimental groups immediately before (PRE) and at 30, 60, 90, and 120 min after tracheal instillation of $\mathrm{PM}_{2.5}$

\begin{tabular}{lcccr}
\hline & Blank filter $(\mathrm{ms})$ & $10 \mu \mathrm{g}(\mathrm{ms})$ & $20 \mu \mathrm{g}(\mathrm{ms})$ & $50 \mu \mathrm{g}(\mathrm{ms})$ \\
\hline SDNN PRE & $4.04 \pm 2.07$ & $5.32 \pm 4.18$ & $4.42 \pm 2.15$ & $7.31 \pm 4.19$ \\
SDNN 30 & $4.83 \pm 2.77$ & $5.16 \pm 4.47$ & $3.37 \pm 1.84$ & $4.31 \pm 2.36$ \\
SDNN 60 & $4.17 \pm 2.18$ & $5.48 \pm 3.62$ & $5.31 \pm 3.93$ & $4.70 \pm 3.05$ \\
SDNN 90 & $4.00 \pm 2.35$ & $5.31 \pm 4.99$ & $5.53 \pm 4.52$ & $3.91 \pm 3.58$ \\
SDNN 120 & $4.12 \pm 2.52$ & $4.08 \pm 3.68$ & $5.10 \pm 3.94$ & $3.88 \pm 3.36$ \\
\hline
\end{tabular}

Data are reported as means \pm SD (in milliseconds) for 10 rats in each group.

Table 3. Heart rate for all experimental groups immediately before (PRE) and at 30,60, 90, and 120 min after tracheal instillation of $\mathrm{PM}_{2.5}$.

\begin{tabular}{lccrr}
\hline & Blank filter (bpm) & $10 \mu \mathrm{g}(\mathrm{bpm})$ & $20 \mu \mathrm{g}(\mathrm{bpm})$ & $50 \mu \mathrm{g} \mathrm{(bpm)}$ \\
\hline HR PRE & $369.72 \pm 58.58$ & $371.62 \pm 53.68$ & $341.31 \pm 64.50$ & $373.93 \pm 27.61$ \\
HR 30 & $354.61 \pm 57.13$ & $374.14 \pm 39.03$ & $345.79 \pm 57.63$ & $363.29 \pm 42.91$ \\
HR 60 & $360.03 \pm 59.93$ & $370.50 \pm 35.21$ & $360.19 \pm 65.92$ & $377.22 \pm 47.81$ \\
HR 90 & $352.69 \pm 47.45$ & $360.65 \pm 29.55$ & $381.83 \pm 58.84$ & $388.26 \pm 45.26$ \\
HR 120 & $357.39 \pm 44.66$ & $358.74 \pm 38.19$ & $380.51 \pm 59.74$ & $392.59 \pm 56.01$ \\
\hline
\end{tabular}

Data are reported as means \pm SD (in beats per minute) for 10 rats in each group.

Table 4. Absolute values of each ECG wave segment duration (P, PR, QRS, and QT) for all experimental groups immediately before (PRE) and at 30,60, 90, and 120 min after tracheal instillation of $\mathrm{PM}_{2.5}$.

\begin{tabular}{lccrr}
\hline & Blank filter $(\mathrm{ms})$ & $10 \mu \mathrm{g}(\mathrm{ms})$ & $20 \mu \mathrm{g}(\mathrm{ms})$ & $50 \mu \mathrm{g}(\mathrm{ms})$ \\
\hline P PRE & $25.42 \pm 3.20$ & $26.07 \pm 4.05$ & $30.58 \pm 2.09$ & $27.93 \pm 3.35$ \\
P 30 & $25.57 \pm 3.53$ & $24.45 \pm 3.06$ & $30.66 \pm 2.00$ & $27.22 \pm 3.61$ \\
P 60 & $25.10 \pm 2.68$ & $23.79 \pm 1.99$ & $30.06 \pm 2.07$ & $27.36 \pm 3.15$ \\
P 90 & $25.71 \pm 3.00$ & $24.20 \pm 2.28$ & $29.02 \pm 2.19$ & $26.96 \pm 3.52$ \\
P 120 & $26.26 \pm 3.39$ & $49.12 \pm 3.12$ & $29.05 \pm 2.38$ & $26.48 \pm 3.46$ \\
PR PRE & $49.74 \pm 3.90$ & $49.62 \pm 2.82$ & $52.75 \pm 5.09$ & $49.77 \pm 5.14$ \\
PR 30 & $49.64 \pm 4.25$ & $49.17 \pm 2.44$ & $52.81 \pm 6.72$ & $49.75 \pm 5.79$ \\
PR 60 & $50.08 \pm 5.09$ & $49.15 \pm 2.64$ & $51.90 \pm 8.57$ & $49.15 \pm 6.18$ \\
PR 90 & $49.57 \pm 3.67$ & $21.49 \pm 2.75$ & $51.18 \pm 9.28$ & $48.34 \pm 5.95$ \\
PR 120 & $49.74 \pm 4.09$ & $21.47 \pm 2.01$ & $26.24 \pm 2.40$ & $47.33 \pm 6.20$ \\
QRS PRE & $22.80 \pm 2.32$ & $21.76 \pm 1.60$ & $25.57 \pm 2.40$ & $24.07 \pm 2.04$ \\
QRS 30 & $22.84 \pm 2.32$ & $21.83 \pm 1.74$ & $25.76 \pm 2.23$ & $23.44 \pm 1.38$ \\
QRS 60 & $22.79 \pm 2.07$ & $21.66 \pm 1.76$ & $25.02 \pm 2.74$ & $23.18 \pm 1.16$ \\
QRS 90 & $22.91 \pm 2.04$ & $103.57 \pm 19.93$ & $23.65 \pm 1.72$ \\
QRS 120 & $22.89 \pm 2.03$ & $103.39 \pm 14.30$ & $119.75 \pm 32.85$ & $22.73 \pm 1.62$ \\
QT PRE & $108.09 \pm 32.27$ & $102.71 \pm 9.92$ & $116.84 \pm 24.48$ & $106.23 \pm 7.10$ \\
QT 30 & $110.10 \pm 29.85$ & $104.89 \pm 8.00$ & $110.97 \pm 29.79$ & $110.27 \pm 14.67$ \\
QT 60 & $111.76 \pm 32.21$ & $102.33 \pm 21.07$ & $107.21 \pm 18.45$ \\
QT 90 & $110.68 \pm 27.58$ & $103.28 \pm 25.16$ & $103.46 \pm 16.07$ \\
QT 120 & $109.80 \pm 23.37$ & & $103.91 \pm 20.38$ \\
\hline
\end{tabular}

Data are reported as means \pm SD (in milliseconds) for 10 rats in each group. 
Table 5. Variations in relation to pre-instillation time (PRE) of each ECG wave segment duration (P, PR, QRS, and QT) for all experimental groups at 30,60, 90, and 120 min after tracheal instillation of $\mathrm{PM}_{2.5}$.

\begin{tabular}{|c|c|c|c|c|}
\hline & Blank filter (ms) & $10 \mu \mathrm{g}(\mathrm{ms})$ & $20 \mu \mathrm{g}(\mathrm{ms})$ & $50 \mu \mathrm{g}(\mathrm{ms})$ \\
\hline P 30 & $1.02 \pm 0.06$ & $0.95 \pm 0.98$ & $1.01 \pm 0.03$ & $0.98 \pm 0.05$ \\
\hline P 60 & $1.00 \pm 0.06$ & $0.93 \pm 0.13$ & $0.99 \pm 0.06^{*}$ & $0.98 \pm 0.06^{*}$ \\
\hline P 90 & $1.02 \pm 0.04$ & $0.95 \pm 0.14$ & $0.95 \pm 0.06^{*}$ & $0.98 \pm 0.07^{*}$ \\
\hline P 120 & $1.04 \pm 0.05$ & $0.97 \pm 0.13$ & $0.95 \pm 0.07^{*}$ & $0.96 \pm 0.08^{*}$ \\
\hline PR 30 & $1.00 \pm 0.03$ & $1.01 \pm 0.04$ & $1.00 \pm 0.04$ & $1.00 \pm 0.04$ \\
\hline PR 60 & $1.01 \pm 0.05$ & $1.00 \pm 0.05$ & $0.99 \pm 0.06^{+}$ & $0.99 \pm 0.05^{+}$ \\
\hline PR 90 & $1.00 \pm 0.03$ & $1.00 \pm 0.06$ & $0.98 \pm 0.07^{+}$ & $0.97 \pm 0.05^{+}$ \\
\hline PR 120 & $1.00 \pm 0.05$ & $0.98 \pm 0.09$ & $0.96 \pm 0.08^{+}$ & $0.95 \pm 0.05^{+}$ \\
\hline QRS 30 & $1.01 \pm 0.04$ & $1.01 \pm 0.10$ & $0.98 \pm 0.04$ & $0.98 \pm 0.05$ \\
\hline QRS 60 & $1.01 \pm 0.03$ & $1.03 \pm 0.10$ & $0.99 \pm 0.04$ & $0.97 \pm 0.07$ \\
\hline QRS 90 & $1.01 \pm 0.05$ & $1.03 \pm 0.09$ & $0.97 \pm 0.07^{+}$ & $0.99 \pm 0.07$ \\
\hline QRS 120 & $1.01 \pm 0.05$ & $1.03 \pm 0.13$ & $0.95 \pm 0.05^{+}$ & $0.95 \pm 0.06^{+}$ \\
\hline QT 30 & $1.03 \pm 0.13$ & $1.01 \pm 0.10$ & $1.00 \pm 0.14$ & $1.04 \pm 0.08$ \\
\hline QT 60 & $1.04 \pm 0.12$ & $1.02 \pm 0.16$ & $0.94 \pm 0.12^{+}$ & $1.00 \pm 0.13^{+}$ \\
\hline QT 90 & $1.04 \pm 0.12$ & $1.05 \pm 0.20$ & $0.87 \pm 0.14^{+}$ & $0.97 \pm 0.11^{+}$ \\
\hline QT 120 & $1.05 \pm 0.20$ & $1.07 \pm 0.23$ & $0.87 \pm 0.11^{+}$ & $0.98 \pm 0.16^{+}$ \\
\hline
\end{tabular}

Data are reported as means $\pm S D$ (in milliseconds) for 10 rats in each group. ${ }^{*} P<0.001$ compared to blank filter; ${ }^{+} P<0.001$ compared to blank filter and $10 \mu \mathrm{g} \mathrm{PM} 2.5$ (Bonferroni test).

wave segment durations measured ( $P, P R, Q R S$, and QT) for all experimental groups and periods of analysis. P wave duration decreased significantly with time in animals receiving 20 and $50 \mu \mathrm{g} \mathrm{PM} \mathrm{P}_{2.5}$ compared to the blank filter group $(P<0.001)$. $P R$ interval duration decreased significantly in animals receiving 20 and $50 \mu \mathrm{gM}_{2.5}$ compared to blank filter and $10 \mu \mathrm{g}(\mathrm{P}<0.001)$. QRS interval duration was reduced among animals that received 20 and $50 \mu \mathrm{gPM}_{2.5}$ in relation to blank filter and 10 $\mu \mathrm{g}(P<0.001)$. However, the groups showed no effect with time for $Q R S$ interval duration $(P=0.057)$. QT interval duration decreased significantly $(P<0.001)$ with time in animals receiving 20 and $50 \mu \mathrm{PM}_{2.5}$ compared to the blank filter and $10 \mu \mathrm{g} \mathrm{PM}_{2.5}$ groups $(\mathrm{P}<0.001)$. We observed a time-dependent decrease of QT interval duration that was more pronounced in animals receiving 20 $\mu \mathrm{g}$ compared to $50 \mu \mathrm{PM}_{2.5}(\mathrm{P}<0.001)$

\section{Discussion}

In this study, tracheal instillation of $\mathrm{PM}_{2.5}$, even at low doses, induced ECG changes expressed by reduced cardiac conduction time in young and healthy rats within a short period of time. We demonstrated in a recent study that the concentration of $\mathrm{PM}_{2.5}$ mass collected at the monitoring station and from the roof of the São Paulo Medical School revealed that $\mathrm{PM}_{2.5}$ emission values were about $30 \mu \mathrm{g} / \mathrm{m}^{3}$ in most of our daily measures (35). Our results indicate a trend of reduction in $\mathrm{HRV}$ that was observed with a major dose $(50 \mu \mathrm{g})$ of $\mathrm{PM}_{2.5}$, close to ambient levels of downtown São Paulo. This result was similar to that obtained in a previous study (30) that demonstrated a decrease in HRV 60 min after tracheal instillation of $50 \mu \mathrm{PM}_{2.5}$. Our main objective was to continue these analyses, assessing acute ECG alterations caused by ambient particle concentrations similar to real conditions.

ECG changes occurred 60 min after $\mathrm{PM}_{2.5}$ instillation, reflecting an acute myocardial response. Despite the differences between an experimental study and real-world environmental conditions, our results support the view that air pollution adversely affects cardiovascular systems. Epidemiological studies support the evidence that these alterations occur within a short period of time $(24 \mathrm{~h})$ and may increase the risk of arrhythmia development and sudden cardiac death. It is interesting to note that the time course of the ECG alterations in our healthy rats $(2 \mathrm{~h})$ was within the same time window as observed in clinical studies on patients with portable defibrillators or survivors of myocardial infarction $(36,37)$. Peters et al. $(26)$ showed that patients with implanted cardioverter defibrillators experienced potentially life-threatening arrhythmias shortly after an $18 \mu \mathrm{gg} / \mathrm{m}^{3}$ increase in air $\mathrm{PM}_{2.5}$ concentration. These findings suggest an increased sympathetic tonus or direct effect of fine particulate matter on cardiac ionic channels. Both are possible mechanisms by which PM 
could lead to arrhythmias or ischemic events $(38,39)$.

As a general rule, particles elicited an increase in HR with major doses of $\mathrm{PM}_{2.5}(20$ and $50 \mu \mathrm{g})$, the most significant effect being observed in the QT interval. This finding indicates that depolarization and repolarization occur more rapidly across ventricular tissue, a condition that may favor the development of arrhythmia and increase oxygen demand in myocardial tissue. Cardiac death is a consequence of a complex interplay between the autonomic nervous system, altered myocardial substrate and myocardial vulnerability leading to arrhythmogenic or ischemic responses. Within this context, evaluation of electrocardiographic parameters provides the opportunity to assess some of the key components related to cardiac death due to these events. Depolarization and repolarization abnormalities assessed by wave interval duration reflect the myocardial substrate state and are associated with an increase of cardiac events in healthy or post-infarction patients (40) after exposure to air pollution.

It is important to characterize the limitations of our study in order to better evaluate its real contribution. Extraction of $\mathrm{PM}_{2.5}$ using distilled water does not preserve all of its components, such as volatile compounds, organic and inorganic insoluble substances and transition metals. In addition, alveolar $\mathrm{PM}_{2.5}$ deposition by tracheal instillation of an aqueous suspension differs from inhalation in real world conditions. Thus, it is difficult to extrapolate experimental conditions involving animals to real world conditions involving humans. For example, respiratory depression is a typical and common effect provoked by anesthetics. In real ambient conditions, these effects will vary according to individual health and exercise training. Because of the "non-real world exposure" approach employed in this study, we were limited in the number of characterizations performed (such as some gases or organic elements). Although we cannot ignore that gases and some other ambient factors could have influenced our results, we believe that particle emission is an important factor that influences our results. The urban particulate matter of São Paulo has been characterized as typically vehicular in origin. In fact, similar to our previous study (30), sulfur was the most representative element demonstrated by $\mathrm{PM}_{2.5}$ elemental analysis.

Our results indicate that a very simple approach - ECG measurements in rats - may represent a noninvasive and non-lethal approach to the evaluation of particle toxicity in the cardiovascular system. Such an approach is necessary because of the complexity of these studies for which human experiments would not be possible. Urban aerosol is a complex mixture of air toxins, the composition of which varies in time and space due to dynamic traffic density, weather conditions, and photochemistry. Thus, a large number of studies, with corresponding chemical analysis, should be performed to better understand the components with higher toxicity, aiming both to describe the mechanisms of injury and to devise strategies of air pollution control in order to reduce risks. The availability of a simple, non-lethal and inexpensive experimental approach that works at near ambient concentrations of particles may be of use to design further experiments to better understand particle-induced toxicity to the cardiovascular system, providing useful information to improve the air quality of our large urban centers.

\section{References}

1. Laden F, Neas LM, Dockery DW, Schwartz J. Association of fine particulate matter from different sources with daily mortality in six U.S. cities. Environ Health Perspect 2000; 108: 941947.

2. Schwartz J, Ballester F, Saez M, Perez-Hoyos S, Bellido J, Cambra K, et al. The concentration-response relation between air pollution and daily deaths. Environ Health Perspect 2001; 109: 1001-1006.

3. Zanobetti A, Schwartz J. The effect of particulate air pollution on emergency admissions for myocardial infarction: a multicity case-crossover analysis. Environ Health Perspect 2005; 113: 978-982.

4. Pope CA III, Muhlestein JB, May HT, Renlund DG, Anderson $\mathrm{JL}$, Horne BD. Ischemic heart disease events triggered by short-term exposure to fine particulate air pollution. Circulation 2006; 114: 2443-2448.

5. Lanki T, Pekkanen J, Aalto P, Elosua R, Berglind N, D'Ippoliti
D, et al. Associations of traffic related air pollutants with hospitalisation for first acute myocardial infarction: the HEAPSS study. Occup Environ Med 2006; 63: 844-851.

6. von Klot S, Peters A, Aalto P, Bellander T, Berglind N, D'Ippoliti $\mathrm{D}$, et al. Ambient air pollution is associated with increased risk of hospital cardiac readmissions of myocardial infarction survivors in five European cities. Circulation 2005; 112: 3073-3079.

7. Dockery DW, Stone PH. Cardiovascular risks from fine particulate air pollution. N Engl J Med 2007; 356: 511-513.

8. van Eeden SF, Yeung A, Quinlam K, Hogg JC. Systemic response to ambient particulate matter: relevance to chronic obstructive pulmonary disease. Proc Am Thorac Soc 2005; 2: 61-67.

9. Delfino RJ, Sioutas C, Malik S. Potential role of ultrafine particles in associations between airborne particle mass and cardiovascular health. Environ Health Perspect 2005; 113: 
934-946.

10. Zeka A, Sullivan JR, Vokonas PS, Sparrow D, Schwartz J. Inflammatory markers and particulate air pollution: characterizing the pathway to disease. Int J Epidemiol 2006; 35: 13471354.

11. Scapellato ML, Lotti M. Short-term effects of particulate matter: an inflammatory mechanism? Crit Rev Toxicol 2007; 37: 461-487.

12. Peters A, Doring A, Wichmann HE, Koenig W. Increased plasma viscosity during an air pollution episode: a link to mortality? Lancet 1997; 349: 1582-1587.

13. Bouthillier L, Vincent R, Goegan P, Adamson IY, Bjarnason $S$, Stewart M, et al. Acute effects of inhaled urban particles and ozone: lung morphology, macrophage activity, and plasma endothelin-1. Am J Pathol 1998; 153: 1873-1884.

14. Widdicombe J, Lee LY. Airway reflexes, autonomic function, and cardiovascular responses. Environ Health Perspect 2001; 109 (Suppl 4): 579-584.

15. Lopshire JC, Zipes DP. Sudden cardiac death: better understanding of risks, mechanisms, and treatment. Circulation 2006; 114: 1134-1136.

16. Podrid PJ, Myerburg RJ. Epidemiology and stratification of risk for sudden cardiac death. Clin Cardiol 2005; 28: I-3-I-11.

17. Burri H, Chevalier $P$, Fayn J, Forlini MC, Rubel $P$, Touboul $P$. Beat-to-beat variations of the electrocardiogram in survivors of sudden death without structural heart disease. J Electrocardiol 2006; 39: 310-314.

18. Billman GE, Kukielka M. Effects of endurance exercise training on heart rate variability and susceptibility to sudden cardiac death: protection is not due to enhanced cardiac vagal regulation. J Appl Physiol 2006; 100: 896-906.

19. Sandercock GR, Brodie DA. The role of heart rate variability in prognosis for different modes of death in chronic heart failure. Pacing Clin Electrophysiol 2006; 29: 892-904.

20. Henneberger A, Zareba W, Ibald-Mulli A, Ruckerl R, Cyrys J, Couderc JP, et al. Repolarization changes induced by air pollution in ischemic heart disease patients. Environ Health Perspect 2005; 113: 440-446.

21. Chevalier P, Burri H, Adeleine P, Kirkorian G, Lopez M, Leizorovicz A, et al. QT dynamicity and sudden death after myocardial infarction: results of a long-term follow-up study. $J$ Cardiovasc Electrophysiol 2003; 14: 227-233.

22. Okin PM, Devereux RB, Howard BV, Fabsitz RR, Lee ET, Welty TK. Assessment of QT interval and QT dispersion for prediction of all-cause and cardiovascular mortality in American Indians: The Strong Heart Study. Circulation 2000; 101: 61-66.

23. Zabel M, Klingenheben T, Franz MR, Hohnloser SH. Assessment of QT dispersion for prediction of mortality or arrhythmic events after myocardial infarction: results of a prospective, long-term follow-up study. Circulation 1998; 97: 2543-2550.

24. Magari SR, Hauser R, Schwartz J, Williams PL, Smith TJ, Christiani DC. Association of heart rate variability with occupational and environmental exposure to particulate air pollution. Circulation 2001; 104: 986-991.

25. Creason J, Neas L, Walsh D, Williams R, Sheldon L, Liao D, et al. Particulate matter and heart rate variability among elderly retirees: the Baltimore 1998 PM study. J Expo Anal
Environ Epidemiol 2001; 11: 116-122.

26. Peters A, Liu E, Verrier RL, Schwartz J, Gold DR, Mittleman $\mathrm{M}$, et al. Air pollution and incidence of cardiac arrhythmia. Epidemiology 2000; 11: 11-17.

27. Peters A, von Klot S, Heier M, Trentinaglia I, Hormann A, Wichmann HE, et al. Exposure to traffic and the onset of myocardial infarction. N Engl J Med 2004; 351: 1721-1730.

28. Mills NL, Tornqvist H, Gonzalez MC, Vink E, Robinson SD, Soderberg S, et al. Ischemic and thrombotic effects of dilute diesel-exhaust inhalation in men with coronary heart disease. N Engl J Med 2007; 357: 1075-1082.

29. Dockery DW, Luttmann-Gibson H, Rich DQ, Link MS, Mittleman MA, Gold DR, et al. Association of air pollution with increased incidence of ventricular tachyarrhythmias recorded by implanted cardioverter defibrillators. Environ Health Perspect 2005; 113: 670-674.

30. Rodriguez Ferreira Rivero DH, Sassaki C, Lorenzi-Filho G, Nascimento Saldiva PH. PM(2.5) induces acute electrocardiographic alterations in healthy rats. Environ Res 2005; 99 : 262-266.

31. Rivero DH, Soares SR, Lorenzi-Filho G, Saiki M, Godleski $\mathrm{JJ}$, Antonangelo L, et al. Acute cardiopulmonary alterations induced by fine particulate matter of São Paulo, Brazil. Toxicol Sci 2005; 85: 898-905.

32. Chalil S, Yousef ZR, Muyhaldeen SA, Smith RE, Jordan P, Gibbs CR, et al. Pacing-induced increase in QT dispersion predicts sudden cardiac death following cardiac resynchronization therapy. J Am Coll Cardiol 2006; 47: 2486-2492.

33. Chen LS, Zhou S, Fishbein MC, Chen PS. New perspectives on the role of autonomic nervous system in the genesis of arrhythmias. J Cardiovasc Electrophysiol 2007; 18: 123-127.

34. Hinds WC. Aerosol technology - properties, behavior and measurement of airborne particles. 2nd edn. New York: Wiley-Interscience; 1998.

35. Mauad T, Rivero DH, de Oliveira RC, Lichtenfels AJ, Guimaraes ET, de Andre PA, et al. Chronic exposure to ambient levels of urban particles affects mouse lung development. Am J Respir Crit Care Med 2008; 178: 721-728.

36. Ruckerl R, Greven S, Ljungman P, Aalto P, Antoniades C, Bellander $\mathrm{T}$, et al. Air pollution and inflammation (interleukin6 , C-reactive protein, fibrinogen) in myocardial infarction survivors. Environ Health Perspect 2007; 115: 1072-1080.

37. Zanobetti A, Schwartz J. Particulate air pollution, progression, and survival after myocardial infarction. Environ Health Perspect 2007; 115: 769-775.

38. Nadziejko C, Fang K, Narciso S, Zhong M, Su WC, Gordon $\mathrm{T}$, et al. Effect of particulate and gaseous pollutants on spontaneous arrhythmias in aged rats. Inhal Toxicol 2004; 16: 373-380.

39. Wichers LB, Nolan JP, Winsett DW, Ledbetter AD, Kodavanti UP, Schladweiler MC, et al. Effects of instilled combustion-derived particles in spontaneously hypertensive rats. Part I: Cardiovascular responses. Inhal Toxicol 2004; 16: 391-405.

40. Zabel M, Acar B, Klingenheben T, Franz MR, Hohnloser SH, Malik M. Analysis of 12-lead T-wave morphology for risk stratification after myocardial infarction. Circulation 2000; 102: $1252-1257$. 